\title{
Influence of intellectual well-being on communal aptitude of adolecents
}

\author{
Ms. Manpreet Kaur \\ (Assistant Professor) \\ Guru Gobind Singh College of Education (For Women), Giddarbaha (Punjab)(India)
}

\begin{abstract}
Every human being, whether a child, an adolescent possesses a unique intellectual well-being which is reflected in all his action toward life. The role of good intellectual well-being in human life is very important for efficient learning and all round development of adolescent. Adolescence is a period of stress and strain and in this period adolescents are marked with a number of problems which effects the intellectual well-being and communal aptitude. For any type of education sound intellectual well-being is the first condition. If adolescents has not sound intellectual well-being, they can't concentrate in learning and retain the knowledge received in class-room learning is dependent on the sound intellectual well-being, well-being adolescents have a desire to acquire more and more information and skills that will give them better control over their environment so intellectual well-being and communal aptitude is as essential to the learning Process as aptitude since intellectual well-being and communal aptitude of adolescents not innate but acquired. Thus good intellectual well-being is most important factor for attaining the communal Aptitude of the adolescents.
\end{abstract}

Keywords: intellectual well-being, communal aptitude, adolescents

\section{Introduction}

Life is a mixture of necessity, freedom, chance, choice and Complexity in life is due to the fast and recent development and competition in each and every field. Modern world or age is the age of science and technology. In spite of so many advancements man is not happy, rather it has made life more complex. Man has become a victim of the confusion and intellectual illness. Majesty of the human beings are dissatisfied, unhappy and discontented and all these factors lead to disturbed intellectual well-being. Everyone knows that sound intellectual well-being is a root of sound habits and habits are formed among children during infancy years. Home is physical unit in a society which exerts a great influence upon the mantel well-being of adolescents. What the individual becomes depends to a large extent on the type of home and society in which he is born and grow up. The training of good behavior which is near to communal aptitude that provided in society and home.

Good intellectual well-being influence the communal Aptitude of a person which has no good intellectual well-being he can't show suitable communal aptitude intellectual well-being and communal aptitude has close relation.

\subsection{Intellectual Well-Being}

Good Well-being depends on the state of both mind and body. Each exerts a direct influence on the other, but giving to the power of mind over nature, good intellectual well-being is supreme importance. It is a complex subject to which justice cannot easily be done to a chapter of limited scope. However, in view of the increasing frequency of intellectual ill well-being and the supreme importance of intellectual well-being for children's successful adjustment and achievement in school. It is necessary on the part of the teacher as well as parents to understand the concept of good intellectual well-being.

The expression 'Intellectual Well-being' consists of two words: Intellectual and Well-being. The word 'Intellectual usually something more than purely cerebral functions of a person, it is also stands for his relationships he establishes with others and a quiet general quality that might be called his equilibrium in his socio-cultural context. Similarly, well-being refers to more than physical well-being, It also denotes the individual intrapsychic balance. The adjustment of his physical structure with his communal functioning.

Intellectual well-being is a state of being which is relative rather than absolute in which a person has effected a reasonably satisfactory integration of his instinctual drives. His integration is acceptable to himself and to his communal milieu as reflected in the satisfactory nature of his interpersonal relationship and level of his communal adjustment. 


\subsection{Indian Concept Of Intellectual Well-Being}

The Indian concept of Intellectual Well-being is available in the Atharava Veda which provides detailed information on intellectual disorders and their treatment. According to atharva ved; human personality on the physical side has three components for 'gunas' as vata, Pitta and Kepha. The intellectual personality on the physical side has three 'gunas' or characteristics satta, Rajas and Tamas. The imbalance of three gunas causes intellectual disorders. Thus normal intellectual well-being means living in 'Rajas' and Tamas to a certain degree.

The charka samhita and susrut also have given to concept of intellectual well-being but they do not differ significantly from Athrava vada.

Concept of intellectual well-being in Ayurveda, well-being means the state of Dhatu samya; Chakak a great Ayurveda holds that the concordance of 'Dhatu' is said to normal well-being and it is the end sought in the employment of medicines as also in the observance of whole some habits so that the equilibrium in 'Dhrtu' may be achieved.

\subsection{Western Concept Of Intellectual Well-Being:-}

American Medical Association (1965) states that Intellectual Well-being includes emotional stability and maturity of characters as well as the strength to withstand the stress of living without undue or persistent symptoms. Physical or psychological, intellectual well-being implies the ability to judge reality accurately and to see things in terms of long term rather short term values. It implies the ability to work in one's chosen field with pleasure and productivity."

The definition finally chosen for intellectual well-being in the present study is the absence of recognizable symptoms of emotional stress, the overt symptoms indicate poor intellectual well-being in terms of inadequacy depression, anxiety, sensitivity, tension and anger. On the contrary good intellectual well-being indicates the term of adequacy. Cheerfulness, placid stability, cool headedness and renascences respectively. These measures have been defined as follows by Wolman (1973).

- Inadequancy:- Inability to deal with a skill or normal ability. However, this description appears to be emphasizing intellectual retardation and not emotional.

- Adequacy:- Ability to deal with a situation with skill and intellectual ability.

- Depression:- Feeling of helplessness inadequacy and sadness.

- Cheerfulness:- Is happy and joyful and has a feeling of self-sufficient.

- Anxiety:- It is unpleasurable experience when the object is lost and the anticipation of being over whelmed by an internal or external forces.

- Placid:- It is a pleasant experience when the object is known and the individual is competent to maintain balance of mind.

- Sensitivity:- The responsiveness of an organism to stimulus energy or the person is not firm and steady and easy to break dawn or give away.

- Stability:- The person is firm and steady and not likely to break down or give away.

- Tension:- A state of equilibrium between the organism and its environment.

- Headedness:- Less firm emotion of anger or burst of anger.

\subsection{Definitions Of Intellectual Well-Being}

- Dutt (1974):- "Intellectual well-being appears as an attribute of mature human personality and communal value to be guarded and maintained through purposefully living."

- J.A. Had Field (1980):- "Intellectual well-being is the full and harmonious functioning of the whole Personality."

- Kamau (1992):- Grouped "Intellectual well-being into three categories as medical, psychological and communal phenomena."

\subsection{Dimensions Of Intellectual Well-Being}

- Positive Self- Evaluation:- Self-confidence, self-acceptance, self-identity, felling of worth wholeness, realization of one's potentialities etc.

- Realistic Perception:- perception free from need distortion, absence of excessive fantasy a broad out look of the work.

- Integration of Personality:- Balance of psychic forces, ability to understand, to share other people's emotions, ability to concentrate at work, task, interest in variety of activities etc.

- Autonomy:- Stable set of interval standards of one's action, self-control in one's action, dependence for own development upon own potentialities rather than on other etc. 
- Group Oriented Attitude:- Ability to get along with others, ability to find recreation, feeling that one is safe in contact with one's groups.

\subsection{Communal Aptitude}

There are various types of aptitude. As society became more complex, Intellectual competences become more sophisticated. This competence is communal aptitude and can be defined as the aptitude that lies behind group interactions and behaviors.

This type of aptitude is closely related to cognition and emotional aptitude and can be also seen as a first level in developing systems aptitude is in applying it to robotic systems and artificial animals (commonly known as animates and artificial) The discipline of communal aptitude enhances the field of artificial aptitude with a variety of theories from system theory adaptive, system, simulation game theory, biologically inspired algorithms, software agents etc.

Research psychologists studying communal cognition and communal neuroscience have discovered many principle which human communal aptitude operatives. In early work on this topic psychologies many center and john Kihlstrem outlined the kinds of concepts people use to make sense of their communal relations and the rules they use to draw inferences.

Psychotherapy often involves helping people to modify their pattern communal aptitude, particularly those that cause them problems in their interpersonal relations. Some efforts are also under way to use computer based interventions to help people develop their own communal aptitude.

\subsection{Definitions Of Communal Aptitude.}

E.L Thorndike (1920) defined communal aptitude as "The ability to understand and manage men and girls to act wisely in human relations."

Moss and Hunt (1927) Defined communal aptitude as the "ability to get along with others."

Gardner (1983) "Advanced Thorndike's ideas of communal aptitude by talking about multiple aptitude including interpersonal aptitude (an ability to understand motivating and managing the self.")

\subsection{Aspect Of Communal Aptitude}

Communal Aptitude or inter personal aptitude concerns the communal 'you' it involve.

Understanding others.

Communal competence

Relationship knows-how.

Understanding Others:- We sometimes call it empathy. We witness it in statements such as "I can just imagine how you must have felt". It means seeing the world as if through another person's eyes. It means being able to read other person's emotion, and to make allowances for them in what we say and do. Empathy, another ability that understanding how a person feels need not dictate haw you act. Being a good listener, for instance, does not mean that you have to agree with everything you listen to, or not get your point of view across. However the benefit of decisions, more choices as to have you behave and a before chance of communicating will and faming good relationship.

Communal aptitude applies universally and not confined to a part of life or a certain type of behavior. However, it usually applies to relationships with family, friend work colleagues and such rather than with passing stranger. It is within closer relationship that people commonly face problems and share felling and it is these cases that most effect on person's goals.

Communal Competences:- This aspect of communal aptitude extends beyond your personal friends. Family and work colleagues. It involves wider Communal groups and the community general communally aptitude people have what we might call, communal consciousness, communal cite racy and a basic concern for others.

Such behavior calls for a high self-worth; you concept yourself as you are; you have nothing to 'prove' $\mathrm{C}$ to the world or to yourself): you are happy in and satisfied in yourself. As with empathy, It depends on your interpersonal aptitude; knowing yourself.

\section{Relationship Know How}

One aspect of communal aptitude is the ability to create and enjoy mutually satisfying relationship. May problems are people problem. Usually it's not what the problem is, but who? Invariably a problem will have more to do with the relationship dimensions of what's going on them with the technical issues. This applies equally in work, family or communal situations. Relationships can spell success or failure in many different contexts. This smart way is to make relationship work for you not against you we can call this relationship know how, successful, long term relationship have to be fostered and maintained.

Thus communal aptitude is ability to understand other people. What motivates them, how they work, how to work cooperatively with them. Successful salespeople, politicians, teachers, clinicians and religious 
leaders are likely to be individuals with high degrees of interpersonal or communal aptitude. At the same time, communal aptitude probably draws on specific internal abilities communal aptitude appears to be receiving the most attention in management and organization psychology literature

\subsection{Objectives Of The Study: -}

\section{Following were the objective of the study}

1. To study the intellectual well-being of adolescents of schools of Sangrur district.

1. To find out the difference in the mean scores of intellectual well-being among adolescents of schools of Sangrur district with respect to sex.

3. To study the communal aptitude of adolescents of schools of Sangrur district.

4. To find out the difference in mean scores of various dimension (factors A, B, C, D, E, F, G, H) of communal aptitude among adolescents of schools of Sangrur district with respect to sex.

5. To find out the relationship between intellectual well-being and communal aptitude (Factors A, B, C, D, E, F, G, H) among adolescents of schools of Sangrur district.

6. To find out the relationship between intellectual well-being and communal aptitude (factors A,B,C,D,E,F,G,H) among male adolescents of schools of Sangrur district.

7. To find out the relationship between intellectual well-being and communal aptitude ( factors A,B,C,D,E,F,G,H) among female adolescents of schools of Sangrur district.

\subsection{Hypotheses Of The Study}

The following were the Hypotheses of the study:-

1. There exists no significant difference in the mean scores of intellectual well-being among adolescents of schools of Sangrur district with respect to sex.

2. There exists no significant difference in the mean scores of various dimensions (factors A,B,C,D,E,F,G,H) of communal aptitude among the adolescents of schools Sangrur district with respect to sex.

3. There exists no significant relationship in the mean scores of intellectual well-being and communal aptitude ( factors A,B,C,D,E,F,G,H) among adolescents of schools of Sangrur district.

4. There exists no significant relationship in the mean scores of mental health and social intelligence (factors A, B , C, D, E, F, G, H) among male adolescents of schools of Sangrur district.

5. There exists no significant relationship in the mean scores of mental health and social intelligence (factors A, B, C, D, E, F, G, H) among female adolescents of schools of Sangrur district.

\subsection{Delimitations Of The Study}

1. The sample study was drawn from adolescents of schools of Sangrur district.

2. The sample was delimited to 60 students of schools of Sangrur district.

3. Further the sample was delimited to 30 male and 30 female adolescents of schools of Sangrur district.

\section{Review Of Related Literature}

In this chapter the modest effort is being made to review the research literature related to intellectual well-being and communal aptitude.

\subsection{Review Related To Intellectual Well-Being:-}

Suman (1985):- Conducted his research on the topic "Intellectual Well-being problems of children in orphanages" he found that rarely one third of the institutionalized children manifested behavioral problems and among those one tenth of the children required well-being personal in the institutional set ups to devise plans for the implementation of intellectual well-being core and training.

Mahadevappa and Parthasarthy (1986):- Conducted a study on the topic "Students potentials for intellectual well-being programmers in India". The findings show that positive changes in the students would have infinite chain reaction resulting in the better human treatment to the problem of intellectual well-being.

Thind, G.K. (1989):- Research on the topic "A study of relationship between job satisfaction and intellectual well-being awareness of teachers" and found that there is significant difference between male and female subjects with regard to various principles of intellectual well-being awareness. Intellectual well-being awareness effects the various dimensions of Job satisfaction.

Kaur, K. (2001):- Study on the topic "A comparative study of attitude of teacher and teachers' trainees towards profession in relation to intellectual well-being." The study was conducted on 200 teachers (30 school teachers and 30 from education college) and concluded that there is significant difference between attitude of teacher towards teaching profession and their intellectual well-being.

Grewal, H.K. (2002):- "A study of teacher effectiveness in relation to intellectual well-being "and found that there is significant relationship exists no b/w effectiveness of teachers working in rural and urban 
areas. There is significant relationship exists no between effectiveness and various dimensions of intellectual well-being of teachers.

Singh P. (2005):- Her study on topic, "Impact of anxiety on Intellectual Well-being" found that there exists no significant difference in anxiety of students of high school with respect to locale. However intellectual well-being scores shows no significant difference with respect to locale. There exists no no significant gender difference among students of high schools with respect to anxiety as well as intellectual well-being.

Singh, S. (2005):- "Impact of scientific attitude on intellectual well-being of adolescent and found that there is no significant relationship between scientific attitude and intellectual well-being among the adolescents.

Sidhu R.K (2006):- "Impact of parental encouragement on intellectual well-being of adolescents" and concluded that there exists no significant relation between intellectual well-being and parental encouragement with respect to locale.

\subsection{Review Related To Communal Aptitude}

Keating (1978):- studied three measures of academic aptitude and three measures of communal aptitude in a group of college students. In the communal domain, factor better at predicting a communal competence criterion than communal measures.

Nutt all (1978):- studied that the more closely spaced younger child was found to be less intelligent. However, these closely spaced children were also found to belong to more athletic terms, to be more interested in getting a Job, to be more ambitious occupationally, to be more self-sufficient, more serious, and more relaxed about protocol. Most of these findings were sufficient only for large family children from two child families.

Freederiksen (1984):- found that rather than trying to place communal aptitude within cognitive abilities taxonomy a separate taxonomy of communal aptitude should be developed.

Marlowe(1985):- discussed the importance of communal aptitude, how to include it in the frame work of other technical training suggesting a prototypical curriculum for communal aptitude development, student competencies and communal aptitude skills for needs assessment.

Chen Shyuefee and Michacl (1993):- found that confirmatory maximum likelihood factor analysis determined how accurately each of several hypothesized combinations of first order and higher order factors reflecting creativity in communal aptitude of 192 high school students described the co variation in selected sub matrixes from the total correlated matrix originally analyses result support Guilford's structure of intellect model.

Parmar, P. (2003) :- "A study of intellectual well-being of adolescents in relation to communal aptitude" and found there exists no significantly difference in the intellectual well-being of high communal intelligent student and average communal aptitude students on the basis of dimensions patience and sense of humor and partially rejected for cooperativeness and confidence and sensitivity.

Liff (2003):- argued that by addressing communal and emotional learning within the class room, college faculty can foster the scholarly as well as interpersonal growth of students. Suggests that sensitivities and learning within the affective domain are strongly linked to the.

Andreou (2006):- found the relational aggression was predicted by cognitive aspects of communal aptitude whereas overt aggression by lack of communal skills.

Wallenivs, Punamaki and Rimpela (2007):- found that the moderating role of communal aptitude was substantiated among older boys: game violence was associated with indirect aggression among those with high level of communal aptitude.

Shobhana M.Zambara (2008):- "Communal competencies of D.Ed trainees in relation to their communal aptitude". The investigator finds that there were more trainees belonging to average communal competencies categories.

\section{Method And Procedure}

"Taking a specific pin pointed problem and trying to find a solution in a scientific manner, is research." Research is serious task, it requires due care to proceed in a definite direction along well defined lines, while conducting any research work, investigators has to take many steps in a well regulate manner.

In a research, there are numerous methods to be used and procedures to be applied. But it is the nature of the problem that determines the adaptation of particular method.

This chapter deals with all the methodological and procedural aspects of the problem. It explains the operational definitions, sample, design, and description of tools along with statistical techniques used for the treatment of the data.

\subsection{Design Of Experiment}

The present study was descriptive survey which was conducted on adolescents of schools of Sangrur district. The study was conducted in different phases. 


\section{PHASE I}

The investigator classified the sample $(\mathrm{N}=60)$ into two categories of male $(\mathrm{N}=30)$ and female $(\mathrm{N}=30)$ students by randomly selecting the adolescents.

\section{PHASES II}

In the second phase of study the investigator measured intellectual well-being and communal aptitude among adolescents in respect to their sex. T-ratio and co-efficient of correlation was calculated.

\subsection{Sampling Of The Study}

The random sampling technique was employed in the present study due to heterogeneous characteristics of the population according to the purpose of study. The criteria of randomization in a sample are met when every individual in the population had the same chance of being chosen for the sample and when selection of our individual or thing has no influence on the choice of another.

In present study keeping the limited source of time and money only 60 adolescents from schools of Sangrur district were randomly selected. Out of selected students 30 male and 30 female were taken from the schools of the Sangrur district.

\subsection{Tools Used} research study.

The selection of suitable tool or instrument is of vital importance from the collection of data in any

- Mental Health check list by pramod kumar (1992)

- Social Intelligence Scale of Dr. N.K. Chadha and Ms. Usha Ganesan (1986)

\subsection{Statistical Techniques Used:-}

1. Descriptive statistical namely mean median and S.D. was done to see the normality to distribution and for seeking the intellectual well-being and Communal Aptitude scores.

2. T-ratio was calculated.

3. Co-efficient of correlation ' $r$ ' was calculated.

\section{Analysis And Interpretation Of Data}

Analysis and interpretation of data require an adequate knowledge of techniques be applied, interpretation is thus by no means a mechanical process. It calls for a critical examination of the analysis of data Scores conclusions. Hence analysis and interpretation being a significant core of research must be given due weightage. Total 60 adolescents were selected from different schools and sample was taken randomly.

Table 4.1 Mean scores of Intellectual Well-being among Male and Female adolescents of Schools of Sangrur district.

\begin{tabular}{|c|c|c|c|c|c|}
\hline Groups & N & Mean & S.D & S.Ed & t-ratio \\
\hline Male & 30 & 17.64 & 3 & \multirow{2}{*}{.548} & $4.30^{* *}$ \\
\hline Female & 30 & 20.00 & 4.59 & \\
\hline
\end{tabular}

**Highly Significant at 0.01 level

Table 4.1 shows mean scores of intellectual heath among male and female adolescents of schools of Sangrur district. The mean scores of male and female adolescents is 17.64 and 20.00 respectively. S.D for male and female is 3 and 4.59 respectively and the value of t-ratio is 4.30 which is highly significant at both levels of confidence i.e 0.05 and 0.01 . There exists no significant difference in the mean scores among male and female adolescents of schools of Sangrur district. It is further observed that Mean scores of intellectual well-being among male adolescents is more favorable than those of female adolescents. This is due to the fact that boys get more exposure, more opportunities to escape from conflicting situation. Hence male adolescents are more intellectually well-being than female adolescents.

Hence Hypothesis stating "There exists no significant difference in the mean scores of intellectual well-being among adolescents of Sangrur district with respect to sex" stands rejected.

Table 4.2(a)

Mean scores of Factor A (Patience) of Communal Aptitude among Male and Female adolescents of Schools of Sangrur district.

\begin{tabular}{|c|c|c|c|c|c|}
\hline Groups & N & Mean & S.D & S.Ed & \multirow{2}{*}{ t-ratio } \\
\cline { 1 - 4 } Male & 30 & 18.13 & 3.25 & \multirow{2}{*}{.564} & $4.50^{* *}$ \\
\hline Female & 30 & 20.67 & 4.62 & & \\
\hline
\end{tabular}

**Highly Significant at 0.01 level 
Table 4.2 (a) shows mean scores of Factor A (Patience) of Communal Aptitude among male and female adolescents of schools of Sangrur District. The mean scores of male and female adolescents is 18.13 and 20.67 respectively. S.D for male and female is 3.25 and 4.62 respectively and the value of t-ratio is 4.50 which is highly significant at both levels of confidence i.e 0.05 and 0.01 . Thus there exists no significant difference in the mean scores of male and female adolescents' schools of Sangrur District. It is further observed that mean scores of Factor A (Patience) of Communal Aptitude among the female adolescents is more favorable than those of Male adolescents. This is due to the fact that female have more patience then that of male. Hence female adolescents are more communally intelligent then male adolescents

Hence hypothesis stating "There exists no significant difference in the mean scores of Factor A (Patience) of communal aptitude among adolescents of schools of Sangrur District with respect to sex" stands rejected.

Table 4.2 (b)

Mean scores of Factor B (Cooperativeness) of Communal Aptitude among Male and Female adolescents of Schools of Sangrur district.

\begin{tabular}{|c|c|c|c|c|c|}
\hline Groups & N & Mean & S.D & S.Ed & t-ratio \\
\hline Male & 30 & 19.17 & 3.99 & \multirow{2}{*}{.618} & $2.55^{*}$ \\
\hline Female & 30 & 20.75 & 4.72 & & \\
\hline
\end{tabular}

* Significant at 0.05 level

Table 4.2 (b) shows mean scores of Factor B (Cooperativeness) of communal Aptitude among male and female adolescents of schools of Sangrur district. The mean scores of male and female adolescents is 19.17 and 20.75 respectively. S.D for male and female is 3.99 and 4.72 respectively and the value of t-ratio is 2.55 which is significant at 0.05 level of confidence. Thus there exists no significant difference in the mean scores of male and female adolescents of schools of Sangrur district. It is further observed that Mean scores of Factor B (cooperativeness) of Communal Aptitude among the Female adolescents are more favorable than those of Male adolescents. This is due to the fact that female have more Co-operativeness than that of male adolescents. Hence female adolescents are more communally intelligent than that of Male adolescents.

Hence hypothesis stating "There exists no significant difference in the mean scores of Factor B (Cooprativeness) of communal Aptitude among adolescents of schools of Sangrur district with respect to sex" stands partially rejected.

Table 4.2(c)

Mean scores of Factor C (Confidence) of Communal Aptitude among Male and Female adolescents of Schools of Sangrur District.

\begin{tabular}{|c|c|c|c|c|c|}
\hline Groups & $\mathbf{N}$ & Mean & S.D & S.Ed & t-ratio \\
\hline Male & 30 & 19.77 & 4.31 & \multirow{2}{*}{.523} & \multirow{2}{*}{$4.47 * *$} \\
\hline Female & 30 & 17.43 & 2.98 & & \\
\hline
\end{tabular}

**Highly Significant at 0.01 level

Table 4.2 (c) shows mean scores of Factor C (Confidence) of Communal Aptitude among male and female adolescents of schools of Sangrur District. The mean scores of male and female adolescents is 19.77 and 17.43 respectively. S.D for male and female is 4.31 and 2.98 respectively and the value of t-ratio is 4.47 which is highly significant at both level of confidence i.e 0.05 and 0.01 . Thus there exists no significant difference in the mean scores of male and female adolescents of schools of Sangrur District. It is further observed that mean scores of Factor $\mathrm{C}$ (Confidence) of Communal Aptitude among the male adolescents are more favorable than those of female adolescents. This is due to the fact that males have more confidence than that of female adolescents. Hence male adolescents are more communally intelligent than that of female adolescents.

Hence hypothesis stating "There exists no significant difference in the mean scores of Factor C (Confidence) of communal Aptitude among adolescents of schools of Sangrur District with respect to sex" stands rejected.

Table 4.2 (d)

Mean scores of Factor D (Sensitivity) of Communal Aptitude among Male and Female adolescents of Schools of Sangrur district.

\begin{tabular}{|c|c|c|c|c|c|}
\hline Groups & N & Mean & S.D & S.Ed & t-ratio \\
\hline Male & 30 & 19.34 & 4.17 & \multirow{2}{*}{.52} & $2.92 * *$ \\
\hline Female & 30 & 17.84 & 3.17 & & \\
\hline
\end{tabular}

** Significant at 0.01 level 
Table 4.2(d) shows mean scores of Factor D (Sensitivity) of Communal Aptitude among male and female adolescents of schools of Sangrur District. The mean scores of male and female adolescents is 19.34 and 17.84 respectively. S.D for male and female is 4.17 and 3.17 respectively and the value of t-ratio is 2.92 which is significant at both level of confidence i.e 0.05 and 0.01 . Thus there exists no significant difference in the mean scores of male and female adolescents of schools of Sangrur District. It is further observed that mean scores of Factor D (Sensitivity) of communal Aptitude among the male adolescents are more favorable than those of female adolescents. This is due to the fact that female are more sensitive than that of male adolescents. Hence male adolescents are more communally intelligent than that of female adolescents.

Hence hypothesis stating "There exists no significant difference in the mean scores of Factor D (Sensitivity) of communal Aptitude among adolescents of schools of Sangrur district with respect to sex" stands rejected.

Table 4.2 (e)

Mean scores of Factor E (Recognition of Communal Environment) of Communal Aptitude among Male and Female adolescents of Schools of Sangrur district.

\begin{tabular}{|c|c|c|c|c|c|}
\hline Groups & $\mathbf{N}$ & Mean & S.D & S.Ed & t-ratio \\
\hline Male & 30 & .89 & .086 & \multirow{2}{*}{.013} & $10^{* *}$ \\
\hline Female & 30 & 1.02 & .099 & & \\
\hline
\end{tabular}

** Highly Significant at 0.01 level

Table 4.2(e) shows mean scores of Factor E (Recognition of Communal Environment) of communal Aptitude among male and female adolescents of schools of Sangrur district. The mean scores of male and female adolescents is .89 and 1.02 respectively. S.D for male and female is 0.86 and 0.99 respectively and the value of t-ratio is 2.92 which is significant at both level of confidence i.e 0.05 and 0.01 . Thus there exists no significant difference in the mean scores of male and female adolescents of schools of Sangrur district. It is further observed that mean scores of Factor E of Communal Aptitude among the female adolescents are more favorable than those of male adolescents. This is due to the fact that female have more recognition of communal environment than that of male adolescents. Hence female adolescents are more communally intelligent than that of male adolescents.

Hence hypothesis stating "There exists no significant difference in the mean scores of Factor E (Recognition of Communal Environment) of communal Aptitude among adolescents of schools of Sangrur district with respect to sex" stands rejected.

Table 4.2 (f)

Mean scores of Factor $\mathbf{F}$ (Tactfulness) of Communal Aptitude among Male and Female adolescents of Schools of Sangrur District.

\begin{tabular}{|c|c|c|c|c|c|}
\hline Groups & $\mathbf{N}$ & Mean & S.D & S.Ed & t-ratio \\
\hline Male & 30 & 12.56 & 1.64 & \multirow{2}{*}{.258} & \multirow{2}{*}{$4.19^{* *}$} \\
\hline Female & 30 & 13.64 & 2.00 & & \\
\hline
\end{tabular}

** Highly Significant at 0.01 level

Table 4.2(f) shows Mean scores of Factor F (Tactfulness) of communal Aptitude among Male and Female adolescents of schools of Sangrur District. The Mean scores of Male and Female adolescents is 12.56 and 13.64 respectively. S.D for male and female is 1.64 and 2.00 respectively and the value of t-ratio is 4.19 which is significant at both level of confidence i.e 0.05 and 0.01 . Thus there exists no significant difference in the mean scores of male and female adolescents of schools of Sangrur district. It is further observed that mean scores of Factor F (Tactfulness) of communal Aptitude among the Female adolescents are more favorable than those of male adolescents. This is due to the fact that female have more tactfulness than that of male adolescents. Hence Female adolescents are more communally intelligent than that of Male adolescents.

Hence hypothesis stating "There exists no significant difference in the mean scores of Factor F (Tactfulness) of communal aptitude among adolescents of schools of Sangrur district with respect to sex" stands rejected.

Table $4.2(\mathrm{~g})$

Mean scores of Factor $\mathbf{G}$ (Sense of Humour) of Communal Aptitude among Male and Female adolescents of Schools of Sangrur District.

\begin{tabular}{|c|c|c|c|c|c|}
\hline Groups & N & Mean & S.D & S.Ed & \multirow{2}{*}{ t-ratio } \\
\hline Male & 30 & 15.73 & 2.91 & \multirow{2}{*}{$3.10^{* *}$} \\
\cline { 1 - 3 } Female & 30 & 14.62 & 2.09 & & \\
\hline
\end{tabular}

** Significant at 0.01 level 
Table 4.2(g) shows mean scores of Factor G (Sense of Humour) of communal Aptitude among male and female adolescents of schools of Sangrur district. The mean scores of male and female adolescents is 15.73 and 14.62 respectively. S.D for male and female is 2.91 and 2.09 respectively and the value of t-ratio is 3.10 which is significant at both level of confidence i.e 0.05 and 0.01 . Thus there exists no significant difference in the mean scores of male and female adolescents of schools of Sangrur District. It is further observed that mean scores of Factor G (Sense of Humour) of communal Aptitude among the male adolescents are more favorable than those of female adolescents. This is due to the fact that male have more sense of humor than that of female adolescents. Hence male adolescents are more communally intelligent than that of female adolescents.

Hence hypothesis stating "There exists no significant difference in the mean scores of Factor G (Sense of Humour) of communal aptitude among adolescents of schools of Sangrur district with respect to sex" stands rejected.

Table $4.2(\mathrm{~h})$

Mean scores of Factor $\mathbf{H}$ (Memory) of Communal Aptitude among Male and Female adolescents of Schools of Sangrur District.

\begin{tabular}{|c|c|c|c|c|c|}
\hline Groups & $\mathbf{N}$ & Mean & S.D & S.Ed & t-ratio \\
\hline Male & 30 & 3.64 & .79 & \multirow{2}{*}{.126} & \multirow{2}{*}{$8.09^{* *}$} \\
\hline Female & 30 & 4.66 & .99 & & \\
\hline
\end{tabular}

** Significant at 0.01 level

Table 4.2(h) shows mean scores of Factor H (Memory) of communal Aptitude among male and female adolescents of schools of Sangrur district. The mean scores of male and female adolescents is 3.64 and 4.66 respectively. S.D for male and female is .79 and .99 respectively and the value of t-ratio is 8.09 which is significant at both level of confidence i.e 0.05 and 0.01 . Thus there exists no significant difference in the mean scores of male and female adolescents of schools of Sangrur district. It is further observed that mean scores of Factor H (Memory) of communal Aptitude among the female adolescents are more favorable than those of male adolescents. This is due to the fact that female have more memory than that of male adolescents. Hence female adolescents are more communally intelligent than that of male adolescents.

Hence hypothesis stating "There exists no significant difference in the mean scores of Factor $\mathrm{H}$ (Memory) of Communal Aptitude among adolescents of schools of Sangrur District with respect to sex" stands rejected.

Table 4.3 (a)

Coefficient of Correlation between Intellectual Well-being and Factor A (Patience) of Communal Aptitude Among adolescents of Schools of Sangrur District. (Total Sample)

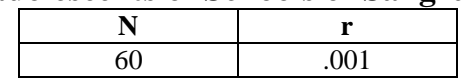

T able 4.3 (a) represents Coefficient of Correlation of Intellectual well-being and Factor A (Memory) of Communal Aptitude among adolescents of Schools of Sangrur District. The Coefficient of Correlation is .001 which is not significant at either levels of confidence i.e 0.05 and 0.01 . This indicates that there exists no no significant relationship between Intellectual well-being and Factor A (Memory) of Communal Aptitude among adolescents of Schools of Sangrur District.

Hence Hypothesis Stating "There exists no significant relationship between Intellectual well-being and Factor A (Memory) of Communal Aptitude among adolescents of schools of Sangrur District" stands rejected.

Table 4.3 (b)

Coefficient of Correlation between Intellectual Well-being and Factor B (Cooperativeness) of Communal Aptitude Among adolescents of Schools of Sangrur District. (Total Sample)

\begin{tabular}{|c|c|}
\hline $\mathbf{N}$ & $\mathbf{r}$ \\
\hline 60 & $.195^{* *}$ \\
\hline
\end{tabular}

** Significant at 0.01 level

Table 4.3 (b) represents Coefficient of Correlation of Intellectual well-being and Factor B (Cooperativeness) of Communal Aptitude among adolescents of Schools of Sangrur District. The Coefficient of Correlation is .195 which is significant at both levels of confidence i.e 0.05 and 0.01 . This indicates that there exists no significant relationship between Intellectual well-being and Factor B (Cooperativeness) of Communal Aptitude among adolescents of Schools of Sangrur district. 
Hence Hypothesis Stating "There exists no significant relationship between Intellectual well-being and Factor B (Cooperativeness) of Communal Aptitude among adolescents of schools of Sangrur district" stands rejected.

Table 4.3 (c)

Coefficient of Correlation between Intellectual Well-being and Factor C (Confidence) of Communal Aptitude Among adolescents of Schools of Sangrur District. (Total Sample)

\begin{tabular}{|c|c|}
\hline $\mathbf{N}$ & $\mathbf{r}$ \\
\hline 60 & .091 \\
\hline
\end{tabular}

Table 4.3 (C) represents Coefficient of Correlation of Intellectual well-being and Factor C (Confidence) of Communal Aptitude among adolescents of Schools of Sangrur district. The Coefficient of Correlation is .091 which is not significant at either levels of confidence i.e 0.05 and 0.01 . This indicates that there exists no no significant relationship between Intellectual well-being and Factor C (Confidence) of Communal Aptitude among adolescents of Schools of Sangrur district.

Hence Hypothesis Stating "There exists no significant relationship between Intellectual well-being and Factor C (Confidence) of Communal Aptitude among adolescents of schools of Sangrur district" stands rejected.

Table $4.3(d)$

Coefficient of Correlation between Intellectual Well-being and Factor D (Sensitivity) of Communal Aptitude Among adolescents of Schools of Sangrur District. (Total Sample)

\begin{tabular}{|c|c|}
\hline $\mathbf{N}$ & $\mathbf{r}$ \\
\hline 60 & .028 \\
\hline
\end{tabular}

Table 4.3 (D) represents Coefficient of Correlation of Intellectual well-being and Factor D (Sensitivity) of Communal Aptitude among adolescents of Schools of Sangrur district. The Coefficient of Correlation is .028 which is not significant at either levels of confidence i.e 0.05 and 0.01 . This indicates that there exists no no significant relationship between Intellectual well-being and Factor D (Sensitivity) of Communal Aptitude among adolescents of Schools of Sangrur district.

Hence Hypothesis Stating "There exists no significant relationship between Intellectual well-being and Factor D (Sensitivity) of Communal Aptitude among adolescents of schools of Sangrur district" stands rejected.

Table 4.3 (e)

Coefficient of Correlation between Intellectual Well-being and Factor E (Recognition of Communal Enviornment) of Communal Aptitude Among adolescents of Schools of Sangrur District. (Total Sample)

\begin{tabular}{|c|c|}
\hline $\mathbf{N}$ & $\mathbf{r}$ \\
\hline 60 & $.142 *$ \\
\hline \multicolumn{2}{|c|}{$*$ Significant at 0.05 level } \\
\hline
\end{tabular}

Table 4.3 (e) represents Coefficient of Correlation of Intellectual well-being and Factor E (Recognition of Communal Environment) of Communal Aptitude among adolescents of Schools of Sangrur district. The Coefficient of Correlation is .142 which is significant at 0.05 level of confidence. This indicates that there exists no significant relationship between Intellectual well-being and Factor E (Recognition of Communal Environment) of Communal Aptitude among adolescents of Schools of Sangrur district.

Hence Hypothesis Stating "There exists no significant relationship between Intellectual well-being and Factor E (Recognition of Communal Enviornment) of Communal Aptitude among adolescents of schools of Sangrur district" stands partially rejected.

Table 4.3 (f)

Coefficient of Correlation between Intellectual Well-being and Factor $\mathbf{F}$ (Tactfulness) of Communal Aptitude Among adolescents of Schools of Sangrur District. (Total Sample)

\begin{tabular}{|c|c|}
\hline $\mathbf{N}$ & $\mathbf{r}$ \\
\hline 60 & $.148^{*}$ \\
\hline \multicolumn{2}{|c|}{$*$ Significant at 0.05 level } \\
\hline
\end{tabular}

Table 4.3 (f) represents Coefficient of Correlation of Intellectual well-being and Factor F (Tactfulness) of Communal Aptitude among adolescents of Schools of Sangrur district. The Coefficient of Correlation is .148 which is significant at 0.05 level of confidence. This indicates that there exists no significant relationship 
between Intellectual well-being and Factor F (Tactfulness) of Communal Aptitude among adolescents of Schools of Sangrur district.

Hence Hypothesis Stating "There exists no significant relationship between Intellectual well-being and Factor F (Tactfulness) of Communal Aptitude among adolescents of schools of Sangrur district" stands partially rejected.

Table $4.3(\mathrm{~g})$

Coefficient of Correlation between Intellectual Well-being and Factor $\mathbf{G}$ (Sense of Humour) of Communal Aptitude Among adolescents of Schools of Sangrur District. (Total Sample)

\begin{tabular}{|c|c|}
\hline $\mathbf{N}$ & $\mathbf{r}$ \\
\hline 60 & .102 \\
\hline
\end{tabular}

Table $4.3(\mathrm{~g})$ represents Coefficient of Correlation of Intellectual well-being and Factor G (Sense of Humour) of Communal Aptitude among adolescents of Schools of Sangrur district. The Coefficient of Correlation is .102 which is not significant at either levels of confidence i.e 0.05 and 0.01 . This indicates that there exists no no significant relationship between Intellectual well-being and Factor G (Sense of Humour) of Communal Aptitude among adolescents of Schools of Sangrur district.

Hence Hypothesis Stating "There exists no significant relationship between Intellectual well-being and Factor G (Sense of Humour) of Communal Aptitude among adolescents of schools of Sangrur district" stands rejected.

Table $4.3(\mathrm{~h})$

Coefficient of Correlation between Intellectual Well-being and Factor H (Memory) of Communal Aptitude Among adolescents of Schools of Sangrur District. (Total Sample)

\begin{tabular}{|c|c|}
\hline $\mathbf{N}$ & $\mathbf{r}$ \\
\hline 60 & .132 \\
\hline
\end{tabular}

Table 4.3 (h) represents Coefficient of Correlation of Intellectual well-being and Factor H (Memory) of Communal Aptitude among adolescents of Schools of Sangrur district. The Coefficient of Correlation is .132 which is not significant at either levels of confidence i.e 0.05 and 0.01 . This indicates that there exists no no significant relationship between Intellectual well-being and Factor H (Memory) of Communal Aptitude among adolescents of Schools of Sangrur district.

Hence Hypothesis Stating "There exists no significant relationship between Intellectual well-being and Factor H (Memory) of Communal Aptitude among adolescents of schools of Sangrur district" stands rejected.

Table 4.5 (a)

Coefficient of Correlation between Intellectual Well-being and factor A (Patience) of Communal Aptitude among Male adolescents of schools of Sangrur District.

\begin{tabular}{|c|c|}
\hline $\mathbf{N}$ & $\mathbf{r}$ \\
\hline 30 & .084 \\
\hline
\end{tabular}

Table 4.5 (a) represents Coefficient of Correlation of Intellectual well-being and Factor A (Patience) of Communal Aptitude among Male adolescents of Schools of Sangrur district. The Value of Coefficient of correlation is .084 which shows no Correlation at the both levels of confidence i.e 0.05 and 0.01 .Thus there exists no no significant relationship between Intellectual well-being and Factor A (Patience) of Communal Aptitude among Male adolescents of Schools of Sangrur district.

Hence Hypothesis stating "there exists no significant relationship in the Mean scores of Intellectual well-being and factor A of Communal Aptitude among male adolescents of schools of Sangrur district." stands rejected.

Table 4.5 (b)

Coefficient of Correlation between Intellectual Well-being and Factor B (Cooperativeness) of Communal Aptitude among Male adolescents of schools of Sangrur District.

\begin{tabular}{|c|c|}
\hline $\mathbf{N}$ & $\mathbf{r}$ \\
\hline 30 & .176 \\
\hline
\end{tabular}

Table 4.5 (b) represents coefficient of correlation of Intellectual well-being and Factor B (Cooperativeness) of Communal Aptitude among Male adolescents of Schools of Sangrur district. The value of coefficient of correlation is .176 which shows no correlation at the both levels of confidence i.e 0.05 and 0.01.Thus there exists no no significant relationship between Intellectual well-being and Factor B (Cooperativeness) of Communal Aptitude among male adolescents of Schools of Sangrur district. 
Hence Hypothesis stating "there exists no significant relationship in the Mean scores of Intellectual well-being and factor B (Cooperativeness) of Communal Aptitude among male adolescents of schools of Sangrur district." stands rejected.

Table 4.5 (c)

Coefficient of Correlation between Intellectual Well-being and Factor C (Confidence) of Communal Aptitude among male adolescents of schools of Sangrur District.

\begin{tabular}{|c|c|}
\hline $\mathbf{N}$ & $\mathbf{r}$ \\
\hline 30 & .030 \\
\hline
\end{tabular}

Table 4.5 (c) represents Coefficient of Correlation of Intellectual well-being and Factor C (Confidence) of Communal Aptitude among male adolescents of Schools of Sangrur district. The Value of Coefficient of correlation is .030 which shows no Correlation at the both levels of confidence i.e 0.05 and 0.01.Thus there exists no no significant relationship between Intellectual well-being and Factor C (Confidence) of Communal Aptitude among Male adolescents of Schools of Sangrur district.

Hence Hypothesis stating "there exists no significant relationship in the Mean scores of Intellectual Well-being and factor C (Confidence) of Communal Aptitude among male adolescents of schools of Sangrur district." stands rejected.

Table 4.5 (d)

Coefficient of Correlation between Intellectual Well-being and Factor D (Sensitivity) of Communal Aptitude among Male adolescents of schools of Sangrur District.

\begin{tabular}{|c|c|}
\hline $\mathbf{N}$ & $\mathbf{r}$ \\
\hline 30 & .031 \\
\hline
\end{tabular}

Table 4.5 (d) represents Coefficient of Correlation of Intellectual well-being and Factor D (Sensitivity) of Communal Aptitude among Male adolescents of Schools of Sangrur district. The Value of Coefficient of correlation is .031 which shows no Correlation at the both levels of confidence i.e 0.05 and 0.01.Thus there exists no no significant relationship between Intellectual well-being and Factor D (Sensitivity) of Communal Aptitude among male adolescents of Schools of Sangrur district.

Hence Hypothesis stating "there exists no significant relationship in the mean scores of Intellectual well-being and factor D (Sensitivity) of Communal Aptitude among male adolescents of schools of Sangrur district." Stands rejected.

Table 4.5 (e)

Coefficient of Correlation between Intellectual Well-being and factor E (Recognition of Communal Environment) of Communal Aptitude among Male adolescents of schools of Sangrur District.

\begin{tabular}{|c|c|}
\hline $\mathbf{N}$ & $\mathbf{r}$ \\
\hline 30 & .026 \\
\hline
\end{tabular}

Table 4.5 (e) represents Coefficient of Correlation of Intellectual well-being and Factor E (Recognition of Communal Environment) of Communal Aptitude among male adolescents of Schools of Sangrur district. The value of coefficient of correlation is .026 which shows no Correlation at the both levels of confidence i.e 0.05 and 0.01.Thus there exists no no significant relationship between Intellectual well-being and Factor $\mathrm{E}$ (Recognition of Communal Environment) of communal aptitude among male adolescents of Schools of Sangrur district.

Hence Hypothesis stating "there exists no significant relationship in the Mean scores of Intellectual well-being and factor E of Communal Aptitude among male adolescents of schools of Sangrur district." stands rejected.

Table 4.5 (f)

Coefficient of Correlation between Intellectual Well-being and factor $\mathrm{F}$ (Tactfulness) of Communal Aptitude among Male adolescents of schools of Sangrur District.

\begin{tabular}{|c|c|}
\hline $\mathbf{N}$ & $\mathbf{r}$ \\
\hline 30 & .055 \\
\hline
\end{tabular}

Table 4.5 (f) represents Coefficient of Correlation of Intellectual well-being and Factor F (Tactfulness) of Communal Aptitude among male adolescents of Schools of Sangrur district. The value of coefficient of correlation is .055 which shows no correlation at the both levels of confidence i.e 0.05 and 0.01 . Thus there exists no no significant relationship between Intellectual Well-being and Factor F (Tactfulness) of Communal Aptitude among Male adolescents of Schools of Sangrur district. 
Hence Hypothesis stating "there exists no significant relationship in the Mean scores of Intellectual Well-being and factor F (Tactfulness) of Communal Aptitude among male adolescents of schools of Sangrur District." Stands rejected.

Table $4.5(\mathrm{~g})$

Coefficient of Correlation between Intellectual Well-being and factor G (Sense of Humour) of Communal Aptitude among Male adolescents of schools of Sangrur District.

\begin{tabular}{|c|c|}
\hline $\mathbf{N}$ & $\mathbf{R}$ \\
\hline 30 & .095 \\
\hline
\end{tabular}

Table 4.5 (g) represents Coefficient of Correlation of Intellectual Well-being and Factor G (Sense of Humour) of Communal Aptitude among Male adolescents of Schools of Sangrur district. The value of coefficient of correlation is .095 which shows no correlation at the both levels of confidence i.e 0.05 and 0.01 . Thus there exists no no significant relationship between Intellectual well-being and Factor G (Sense of Humour) of Communal Aptitude among male adolescents of schools of Sangrur district.

Hence Hypothesis stating "there exists no significant relationship in the Mean scores of Intellectual well-being and factor G (Sense of Humour) of Communal Aptitude among male adolescents of schools of Sangrur district." stands rejected.

Table 4.5 (h)

Coefficient of Correlation between Intellectual Well-being and factor $\mathbf{H}$ (Memory) of Communal Aptitude among Male adolescents of schools of Sangrur District.

\begin{tabular}{|c|c|}
\hline $\mathbf{N}$ & $\mathbf{r}$ \\
\hline 30 & .022 \\
\hline
\end{tabular}

Table 4.5 (h) represents Coefficient of Correlation of Intellectual well-being and Factor H (Memory) of Communal Aptitude among male adolescents of Schools of Sangrur district. The value of coefficient of correlation is .022 which shows no correlation at the both levels of confidence i.e 0.05 and 0.01 .Thus there exists no no significant relationship between Intellectual well-being and Factor $\mathrm{H}$ (Memory) of Communal Aptitude among male adolescents of schools of Sangrur district.

Hence Hypothesis stating "there exists no significant relationship in the Mean scores of Intellectual well-being and factor H (Memory) of Communal Aptitude among male adolescents of schools of Sangrur district." stands rejected.

Table 4.6 (a)

Coefficient of Correlation between Intellectual Well-being and factor A (Patience) of Communal Aptitude among Female adolescents of schools of Sangrur District.

\begin{tabular}{|c|c|}
\hline $\mathbf{N}$ & $\mathbf{r}$ \\
\hline 30 & $.224 *$ \\
\hline
\end{tabular}

Table 4.6 (a) represents coefficient of correlation of Intellectual well-being and Factor A (Patience) of Communal Aptitude among female adolescents of schools of Sangrur district. The value of coefficient of correlation is .224 which is significant at 0.05 level of confidence and not significant at 0.01 level of confidence. Thus there exists no significant relationship between Intellectual well-being and factor A (Patience) of Communal Aptitude among female adolescents of schools of Sangrur district. Reason being is there exists no good relation between Intellectual well-being and patience.

Hence Hypothesis stating "there exists no significant relationship in the mean scores of Intellectual well-being and factor A of Communal Aptitude among female adolescents of schools of Sangrur district." stands partially rejected.

Table 4.6 (b)

Coefficient of Correlation between Intellectual Well-being and factor B (Cooperativeness) of Communal Aptitude among Female adolescents of schools of Sangrur District.

\begin{tabular}{|c|c|}
\hline $\mathbf{N}$ & $\mathbf{r}$ \\
\hline 30 & .054 \\
\hline
\end{tabular}

Table 4.6 (b) represents Coefficient of Correlation of Intellectual well-being and Factor B (Cooperativeness) of Communal Aptitude among female adolescents of schools of Sangrur district. The value of coefficient of correlation is .054 which shows no correlation at the both levels of confidence i.e 0.05 and 0.01 . 
Thus there exists no no significant relationship between Intellectual well-being and Factor B (Cooperativeness) of Communal Aptitude among female adolescents of schools of Sangrur district.

Hence Hypothesis stating "there exists no significant relationship in the mean scores of Intellectual well-being and factor B (Cooperativeness) of Communal Aptitude among female adolescents of schools of Sangrur district." stands rejected.

Table 4.6 (c)

Coefficient of Correlation between Intellectual Well-being and factor C (Confidence) of Communal Aptitude among Female adolescents of schools of Sangrur District.



Table 4.6 (c) represents coefficient of correlation of Intellectual well-being and Factor C (Confidence) of Communal Aptitude among female adolescents of schools of Sangrur district. The value of coefficient of correlation is .196 which is significant at 0.05 level of confidence and not significant at 0.01 level of confidence. Thus there exists no significant relationship between Intellectual well-being and factor C (Confidence) of Communal Aptitude among female adolescents of schools of Sangrur district. Reason being there exists no good relation between Intellectual well-being and confidence.

Hence Hypothesis stating "there exists no significant relationship in the mean scores of intellectual well-being and factor C (Confidence) of Communal Aptitude among female adolescents of schools of Sangrur district." stands partially rejected.

Table 4.6 (d)

Coefficient of Correlation between Intellectual Well-being and factor D (Sensitivity) of Communal Aptitude among Female adolescents of schools of Sangrur District.

\begin{tabular}{|c|c|}
\hline $\mathbf{N}$ & $\mathbf{r}$ \\
\hline 30 & .074 \\
\hline
\end{tabular}

Table 4.6 (d) represents coefficient of correlation of Intellectual well-being and Factor D (Sensitivity) of Communal Aptitude among female adolescents of schools of Sangrur District. The value of coefficient of correlation is .074 which shows no correlation at the both levels of confidence i.e 0.05 and 0.01.Thus there exists no no significant relationship between Intellectual well-being and Factor D (Sensitivity) of Communal Aptitude among female adolescents of schools of Sangrur district.

Hence Hypothesis stating "there exists no significant relationship in the mean scores of Intellectual well-being and factor D (Sensitivity) of Communal Aptitude among female adolescents of schools of Sangrur district." stands rejected.

Table 4.6 (e)

Coefficient of Correlation between Intellectual Well-being and factor $\mathbf{E}$ (Recognition of Communal Environment) of Communal Aptitude among Female adolescents of schools of Sangrur District.

\begin{tabular}{|c|c|}
\hline $\mathbf{N}$ & $\mathbf{R}$ \\
\hline 30 & .053 \\
\hline
\end{tabular}

Table 4.6 (e) represents coefficient of correlation of Intellectual well-being and Factor E (Recognition of Communal Enviornment) of Communal Aptitude among female adolescents of Schools of Sangrur district. The value of coefficient of correlation is .053 which shows no correlation at the both levels of confidence i.e 0.05 and 0.01.Thus there exists no no significant relationship between Intellectual well-being and Factor E (Recognition of Communal Environment) of Communal Aptitude among female adolescents of schools of Sangrur district.

Hence Hypothesis stating "there exists no significant relationship in the mean scores of Intellectual well-being and factor E (Recognition of Communal Environment) of Communal Aptitude among female adolescents of schools of Sangrur district." stands rejected.

Table 4.6 (f)

Coefficient of Correlation between Intellectual Well-being and factor F (Tactfulness) of Communal Aptitude among Female adolescents of schools of Sangrur District.

\begin{tabular}{|c|c|}
\hline $\mathbf{N}$ & $\mathbf{r}$ \\
\hline 30 & .126 \\
\hline
\end{tabular}


Table 4.6 (f) represents coefficient of correlation of Intellectual well-being and Factor F (Tactfulness) of Communal Aptitude among female adolescents of Schools of Sangrur district. The value of coefficient of correlation is .126 which shows no correlation at the both levels of confidence i.e 0.05 and 0.01.Thus there exists no no significant relationship between Intellectual well-being and Factor F (Tactfulness) of Communal Aptitude among female adolescents of schools of Sangrur district.

Hence Hypothesis stating "there exists no significant relationship in the mean scores of Intellectual well-being and factor F (Tactfulness) of Communal Aptitude among female adolescents of Sangrur district." stands rejected.

Table $4.6(\mathrm{~g})$

Coefficient of Correlation between Intellectual Well-being and factor G (Sense of Humour) of Communal Aptitude among Female adolescents of schools of Sangrur District.

\begin{tabular}{|c|c|}
\hline $\mathbf{N}$ & $\mathbf{R}$ \\
\hline 30 & .096 \\
\hline
\end{tabular}

Table 4.6 (g) represents coefficient of correlation of Intellectual well-being and Factor G (Sense of Humour) of Communal Aptitude among female adolescents of schools of Sangrur district. The value of coefficient of correlation is .096 which shows no correlation at the both levels of confidence i.e 0.05 and 0.01 . T

hus there exists no no significant relationship between Intellectual well-being and Factor G (Sense of Humour) of Communal Aptitude among female adolescents of schools of Sangrur district.

Hence Hypothesis stating "there exists no significant relationship in the mean scores of Intellectual well-being and factor G (Sense of Humour) of Communal Aptitude among female adolescents of Sangrur district." stands rejected.

Table 4.6 (h)

Coefficient of Correlation between Intellectual Well-being and factor H (Memory) of Communal Aptitude among Female adolescents of schools of Sangrur District.

\begin{tabular}{|c|c|}
\hline $\mathbf{N}$ & $\mathbf{r}$ \\
\hline 30 & .009 \\
\hline
\end{tabular}

Table 4.6 (h) represents coefficient of correlation of Intellectual well-being and Factor H (Memory) of Communal Aptitude among female adolescents of Schools of Sangrur district. The value of coefficient of correlation is .009 which shows no correlation at the both levels of confidence i.e 0.05 and 0.01.Thus there exists no no significant relationship between Intellectual well-being and Factor H (Memory) of Communal Aptitude among female adolescents of Schools of Sangrur district.

Hence Hypothesis stating "there exists no significant relationship in the mean scores of Intellectual well-being and factor $\mathrm{H}$ (Memory) of Communal Aptitude among female adolescents of schools of Sangrur district." stands rejected.

\section{Results And Conclusion}

The study has revealed significant difference between Intellectual Well-being and Communal Aptitude among adolescents with respect to sex. Therefore there is dire need for the teacher and educators to take into account the factors causing poor intellectual well-being. Difference in the mean scores of intellectual well-being was found with respect to their sex. Thus the findings of investigation provide help to the teacher educators, college lecturer, school teachers and parents to help their wards to channelize their energy in useful and productive areas. The parents can be guided to provide congenial awareness at home and understand their children at intellectual as well as communal level. The present study will help the teacher in evaluating the behavior of the student in the light of their intellectual well-being and communal behavior.

\section{Bibliography}

[1]. Alder, H (2000) Boost your aptitude published by Vinod Vasihtha for Kogan page India pvt. Limited, first south Asian edition.

[2]. Anand, S.P. (1989) "Intellectual Well-being of high school students" Buch M.B. fifth survey of educational Research Vol. II, NCERT New Delhi.

[3]. Andoredo and Eleni (2006) "Communal preference perceived popularity and Communal Aptitude Relation to overt and Relational Aggression.” School Psychology international, v27 n3 p339-351 2006 (EJ738911) www.ERIC.com

[4]. Barnes, M and Sternvberg, Robert J. (1986) "Communal aptitude and Decoding of Nonverbal cues." Aptitude, v13 n3 p263-287 JulSep (EJ399789) www.ERIC.com

[5]. Bernard, H.W. (1970) "Intellectual Well-being in the Classroom" New York Mc Graw.

[6]. Best J.W. (1983) "Research in Education" New Delhi Prentice Hall of India.

[7]. Bhagi and Sharma, S. (1992) "Encyclopedia Dictionary of Psychology", New Delhi, Anmol Publication.

[8]. Books and Shaffer (1951) "Communalization of students activator journal of communal issues vol 25 n4 p-35-39

[9]. Brown, Bert and Deursch, Martion(2005) "Some data on Communal influences in Negro-White Aptitude." Vol 26 n2 P.338-351 (ED002475) www.ERIC.com 
[10]. Buch, M.B. (1979) 2nd survey of research in edu. Second edition published by M.B. Society for educational research and developed (India), Modern Printers Ahmedabad. Vol - 1 (1979)

[11]. Buch, M B (1983) Third survey of Research in education national council of educational Research and training Sci Aurobindo Marg, New Delhi. Vol-2 (1983)

[12]. Buch, M B (1989) Forth survey of Research in edu. National council of educational Research and Training Bahadur Shah Zafar Marg, New Delhi. Vol-1 (1989)

[13]. Buch, M.B. (1992) Fifth Survey of Research in Education, Delhi NCERT. Vol-3 (1982)

[14]. C.L.Kundu and D.N.Tutoo (1998) Educational Psychology published by Sterling Publishers Private Limitied, New Delhi, p-110

[15]. Cantor, N. and Kihlstrom, L J.F. (1987) Personality and communal aptitude. Englewood Cliffs, N.J. Prentice-Hall.

[16]. Chen, S.A. and W.B (1993) First Order and higher Order factor of Creative Communal and michael, Aptitude with Guilford's Structure of Intellectual Model: A Reanalysis of a Guilford data Base. Educational and Psychological Measurement, v53 n3 p619-41 Fall 1993

[17]. Conway, M.A. (1990) Autobiographical Memory: An introduction. Milton Keynes, U.K.: Open University Press.

[18]. Cutts Norman, E and Mosely, N (1941) "Partial Hygiene" Mc Graw Hill Book Company.

[19]. Dhaliwal, M.K. (2002-03) “A study of the effect of organizational upon the intellectual well-being of teachers". M.Ed dissertation, Pb. Univ. Chd.

[20]. Dhingra, R (1966) "Educational Psychology and guidance” Punjab Kitab Ghar, Jalandher City. 1970 p. 185-189.

[21]. DR. Prasad, D.C and DR. Prasad, R (2006) Applied Educational Psychology published by KSK Publishers and Distributors, New Delhi. (2007)

[22]. Dr. Chadha, N.K. and Ms. Ganesan, U. (1986) Manual for communal aptitude Scale. National Psychological Corporation, Agra

[23]. Dutt, N.K. (1974)"Psychological Foundation of "Educational." Doaba House Publishers. (1980)

[24]. Encyclopedia of Education Research (1969) International encyclopedia of education Vol 8 Oxford Pergemon.

[25]. Ford, M. E (1883) "The Nature of Communal Aptitude: Processes and Outcomes".(ED243041) www.ERIC.com

[26]. Frederiksen, N. (1984) "The place of Communal Aptitude in a Taxonomy of Cognitive Abilities". Aptitude, V8 n4 p315-37 (EJ309377) www.ERIC.com

[27]. Garbielsne (1992) "The Role of Self Monitoring, Conformity and Communal Aptitude in selection of College Major"(ED347953), www.ERIC.com

[28]. Gill, O. S (2002) "Intellectual Well-being of High School students in Relation to their Parental behavior". M.Ed. Dissertation, Pb. Univ. Chd

[29]. Good, C.V. (2003) Good's Dictionary of education "Dictionary of edu, Mc Graww hill book co. Youk Third edition (P31, 248,253)

[30]. Grewal, H.K. (2001-02) “A study of teacher effectives in Relation to intellectual Well-being” M.Ed. dissertation Pb. Univ. Chd.

[31]. Gupta , S.P. (1987) "Intellectual Need for a National Programmed". Communal Welfare Vol. 34 (9).

[32]. Hadfield, J.A (1952)B "Intellectual Well-being and Psychoneurosis" George Allen Unwin Ltd.

[33]. Kaur, G (1990) "A study of principal of intellectual well-being as practices by Teacher and Teacher Practice as Perceived by Adolescents". M.Ed. issertation, $\mathrm{Pb}$. Univ. Chd.

[34]. Kaur, K. (2001) "A comparative study of attitude of Teachers and Teacher Trainees towards profession in Relation to Intellectual Wellbeing." M.Ed. dissertation, Pb. Univ. Chd

[35]. ..Kaur, N. (2009) "Mental health on social intelligence of adolecents of muktsar district." M.Ed. dissertation, Pb. Univ. Chd

[36]. Kerlinger, F(1973) "Foundation to frustration among adolescents in the school situation" Ph. D. edu, Raj Uni.

[37]. Keeting, D. P, (1978) "A search for communal Aptitude". Journal of Education Psychology, 70,2,218-23, Apr 78 (EJ187994) www.ERIC.com

[38]. Kormer (1962) "Socio Phobia in Intellectual Well-being Teachers College Record.” M.Ed Dissertation Pb. Univ. Chd.

[39]. Kosmitzki, C. and John, O.P. (1962) "The implicit use of explicit conceptions of communal aptitude. Personality \& Individual Differences", v53 n3 p619-41 fall 1962

[40]. Kumar, P. (1992) "Manual for intellectual well-being checklist". National Psychological Corporation Agra.

[41]. Lawkan, P (1949) "Intellectual Hygiene in Public Well-being" McGraw hill, New York.

[42]. Liff, S B. (2003) “Communal and Educational Aptitude: Application for Development Education". Journal of Developintellectual Education, v26 n3 p28-34 Spr 2003 (EJ668422) www.ERIC.com.

[43]. Malhotra (1983) "Intellectual well-being as function of sex and socio economic states". M.Ed. Dissertation, Pb. Univ. Chd.

[44]. Mangotra H.P. (1982) "Intellectual Well-being as a correlate of aptitude education, academic achievement of socio-economic status" Ph.D. Thesis Buch M.B. fifth survey of Educational Research Vol. Li NCERT New Delhi.

[45]. Marlowe, H (1986) “Communal Aptitude: Implications for Adult Education. Lifelong Learning”, v8 n6 p4-5,27 Apr 1985(EJ 314833 ) www.ERIC.com..

[46]. Maslow, (1962) "In the communal sciences Encyclopedia". Adam Kapur and Jessica Kapur, London: Routtedges.

[47]. Misra, G (1989-92) "Fifth Survey of educational research". (1993)

[48]. Oxford English Dictionary Clarendon Press. Oxford, Vol. VI.

[49]. Parmar, P. (2003) "Intellectual well-being of adolescents in relation to communal aptitude". M.Ed. dissertation, Pb. Univ. Chd.

[50]. Prasanna, K.C.B. (1984) "A study of certain Intellectual Well-being variables associated with high and low achieving adolescents" Ph. D. Thesis Much M.B. Survey of research thesis. Much M.B. forth survey of Research in Edu Vol. I NCERT New Delhi.

[51]. Preet, R. (1991) "A study of intellectual well-being of adolescent pupils in relation to divergent configuration of parental behavior" M.Ed. Dissertation, PU. Chd

[52]. Sharma, R.N. (2000) ' 3 rd edition Essentials of Communal Psychology' published by S.S. Chabra for Surjeet Publication.

[53]. Shobana, M.Z (2008) Communal Competencies of D.Ed trainees in relation to their Communal Aptitude.” Edu. Trac. Vol-8 Nov 2008.

[54]. Sidhu, R.K (2006) "Impact of Parental encouragement on Intellectual Well-being of Adolescents.” M..Ed Dissertation, Pb. Univ. Chd

[55]. Singh, P. (2005) "Impact of Anxiety on intellectual well-being". M.Ed. Dissertation, Pb. Univ. Chd.

[56]. Singh, S. (2005) "Impact of scientific attitude on intellectual well-being of adolescents". M.Ed. Dissertation, Pb. Univ. Chd.

[57]. Thind, G.K. (1989) "A study of Relation between job satisfaction and intellectual well-being awareness of Teachers." M.Ed. dissertation. $\mathrm{Pb}$. Univ. Chd.

[58]. Thorndike, R.L. and Stein, S (1937) "An evaluation of the attempts to measure communal aptitude" Psychological Bulletin, 34, p $275-285$.

[59]. Wallenius M.P, Raija,L and Rimpela. A (2007) "Digital game planning and Direct and indirect Aggression in Early adolescent . The role of age, Communal aptitude and parent-child communication" journal of youth and Adolescence. V36 n3 p325-336 Apr 2007(EJ758240) www.ERIC.com 